Revista Espaço do Currículo

ISSN 1983-1579

Doi: 10.22478/ufpb.1983-1579.2019v12n3.46151 http://periodicos.ufpb.br/ojs2/index.php

\title{
POLÍTICAS E CURRÍCULO NA LICENCIATURA EM ARTES VISUAIS: pesquisas do Observatório da Formação de Professores no âmbito do Ensino de Arte (OFPEA/BRARG)
}

\author{
POLICIES AND CURRICULUM IN THE VISUAL ARTS DEGREE: to share research from the Observatório da \\ Formação de Professores no âmbito do Ensino de Arte (OFPEA/BRARG)
}

Maria Cristina da Rosa Fonseca da Silva'

\begin{abstract}
Resumo: $O$ estudo pretende analisar as políticas públicas educacionais que interferem no Ensino de Artes na escola. Utiliza-se igualmente das investigações desenvolvidas pelo projeto em rede Observatório da Formação no âmbito do Ensino de Artes principalmente as situadas no Programa de Pós-Graduação em Artes Visuais PPGAV/UDESC para identificar aspectos mais amplos que atingem a formação de professores de arte nacionalmente. Da mesma forma, busca um comparativo entre as implicações das políticas educacionais na formação docente em artes nas licenciaturas e os respectivos desdobramentos no Ensino de Arte na escola. Considera os modelos de formação docente desenhados nos últimos tempos e implementados nas licenciaturas em artes visuais. Finalmente apresenta reflexões fundamentadas na pedagogia histórico-crítica com a intenção de dar visibilidade às contradições presentes no Ensino de Arte, a partir das especificidades das artes visuais na escola bem como na formação profissional nas licenciaturas.
\end{abstract}

Palavras-chave: Formação. Artes Visuais. Observatório. UDESC.

\section{INTRODUÇÃO}

Minha experiência de professora no magistério público municipal durante 15 anos aliada à atuação como formadora no curso de Licenciatura em Artes Visuais bem como a oferta de assessorias e formação continuada nas redes públicas de ensino e em projetos de extensão alimentaram nos últimos 25 anos a necessidade de investigar a formação de professores. Assim, tanto na minha própria formação acadêmica, quanto nas pesquisas posteriores, o tema da formação de professores de Artes Visuais esteve presente como objeto central de meus estudos e pesquisas na universidade. Considero igualmente que o tema da formação está vinculado às questões históricas de ensinar e aprender arte na escola, e da tarefa da escola, como espaço público de resistência, de distribuir os conhecimentos produzidos pela humanidade, de modo especial, para as camadas sociais mais pobres e que ocupam os últimos patamares de investimento na cena educacional brasileira.

\footnotetext{
${ }^{1}$ Doutora em Engenharia de Produção pela Universidade Federal de Santa Catarina. Professora do Centro de Artes da UDESC. E'mail: cristinaudesc@gmail.com. ORCID: http://orcid.org/0000-0003-1571-9176
}

Keywords: Teacher education. Visual arts. 
SILVA, M. C. R. F.

No ano de 2011, durante a realização de estágio de pós-doutorado na Universidad Nacional de las Artes (UNA), nasce o projeto de pesquisa Observatório da Formação de Professores no âmbito do Ensino de Artes: estudos comparados entre Brasil e Argentina (OFPEA/BRARG). O objetivo do projeto em rede, que agrega universidades no Brasil e na Argentina, foi, inicialmente, mapear a oferta de cursos de Artes Visuais no Brasil e na Argentina, além de analisar as matrizes curriculares das licenciaturas buscando sistematizar e problematizar os conteúdos propostos.

$\mathrm{Na}$ atualidade, o projeto no Brasil se constitui como uma rede que abrange dez universidades e dois institutos federais e aglutina um conjunto de estudos bastante significativos para pensar as licenciaturas em Artes Visuais no País. Assim, organizei o presente artigo a partir das seguintes questões: Como as políticas públicas educacionais influenciam as matrizes curriculares? E que elementos reverberam no Ensino de Artes Visuais na escola? Para responder a estas questões parti do seguinte roteiro de escrita: no primeiro tópico descrevo as principais políticas educacionais que interferem no Ensino de Artes na escola, muitas vezes mediado pela formação proposta nos cursos de Licenciatura em Artes Visuais. No segundo, sistematizo os estudos do Observatório desenvolvidos no PPGAV/UDESC e que analisam as matrizes curriculares de algumas regiões do Brasil e mostram tendências nacionais que conformam um modelo de formação. Finalmente, no terceiro tópico são analisadas as relações das problemáticas abordadas nos tópicos anteriores, evidencio três modelos de formação presentes na escola, teço comparações com o Ensino de Artes Visuais na escola, buscando extrair elementos para uma análise mais aprofundada do Ensino de Artes na atualidade.

\section{POLÍTICAS EDUCACIONAIS E SUA INTERFERÊNCIA NO ENSINO DE ARTE}

Intenciono no presente tópico abordar as relações entre políticas educacionais e o ensino de artes $^{2}$ nas escolas. Essa análise é mediada pela formação docente na graduação e no âmbito do trabalho na rede escolar, particularmente explicitando como a legislação atual interfere na formação docente, direcionando-a para um modelo de flexibilização neoliberal.

Apresento um conjunto de considerações iniciais que pretendem tecer um pano de fundo para análise dos dados coletados. Esse entrelaçamento se sobressai nos objetos criados por Del Pillar Sallun que, segundo Fabris (1999) e Canton (2000), ao se enrolar e desenrolar os fios de latão tornam-se um prolongamento do corpo, que como formas circulares se atam e desatam. Nas palavras de Canton (2000, p. 53-54)

Com nossos olhares, desencantados com as narrativas lineares propostas pelos sistemas de produção estabelecemos uma identificação promíscua com aquele corpo compulsivo, desprovido da possibilidade de escapar de sua vida vazia e incessante trajetória.

Figura 1 - Ataduras, 1997, fio de latão

\footnotetext{
${ }^{2}$ Utilizarei a expressão ensino de arte quando estiver me referindo ao Ensino de Arte na escola que engloba as diferentes áreas (Artes Visuais, Dança, Música e Teatro), porque no Brasil poucos entes públicos contratam profissionais por área específica.
} 


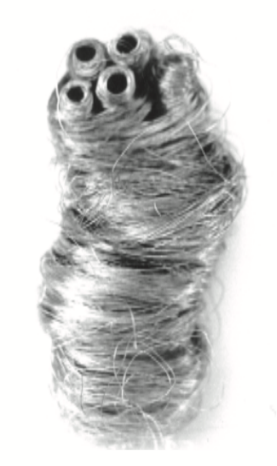

Fonte: (FABRIS, 1999)

Temos aqui a interpretação de uma metáfora, ora nos amarra com seus fios, nos incorporando ao próprio objeto, ora tece outras formas nos impelido a objetos outros, muitas vezes fora de nosso desejo (Figura 1).

É nesse movimento de atar e desatar que nos colocamos como professores diante dos fios/amarras do Estado e suas políticas conformadoras.

Abordar as políticas públicas requer um breve retorno aos anos de 1990, início da implantação mais direta das reformas neoliberais no Brasil. As reformas, que foram implementadas aos poucos, reproduzem uma lógica de expansão da exploração da educação pelo capital. Para construir a reforma no sistema de ensino da América Latina os capitalistas se utilizaram de entidades e organizações bancárias que legitimaram o processo, por exemplo, de pesquisas da UNESCO com o patrocínio do Banco Mundial' ${ }^{3}$, formulando estudos e divulgando-os como verdades, de alguma forma criando um consenso sobre o pensamento educacional e o funcionamento da escola.

O artista Torres Garcia questionou por meio de seu trabalho artístico a ideia de uma América Latina dominada ao propor sua América Invertida (Figura 2), trabalho produzido em 1943.

Figura 2 - América Invertida

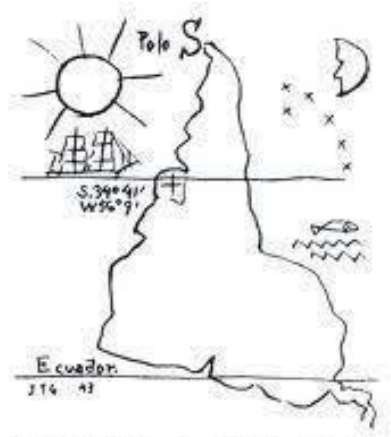

ESCUELA DEL SUR

PUBLICACION DEL TALLER

TORRES - GARCIA

MONTELiDeO

Fonte: Costa (2011)

${ }^{3}$ Sobre o tema, ver Mazzeu (2011). 
O estudo acerca da América Latina nos auxilia a compreender como certos desdobramentos político-educacionais chegam ao Brasil. Mazzeu (2011) ao analisar a reforma dos anos de 1990 no Brasil argumenta que ela teve como objetivo gestar as modificações necessárias para a mudança do perfil do trabalhador, para isso foram criados programas cuja centralidade foi a competitividade e a meritocracia. A autora detalha que esses modelos produtivos de competitividade são pautados na flexibilidade, autonomia e polivalência; acrescento que esse processo de ampliação da exploração se deu de modo mais efetivo nos países pobres da América Latina.

Analisando os termos que aparecem repetidos nos textos das políticas educacionais, muitos deles vindos do mundo empresarial, ressalto que a flexibilidade se dá muito mais no sentido das relações de trabalho, da adaptação a diferentes condições de exploração que produzem inseguranças para o trabalhador, do que no processo de decisão na implementação das políticas. Autonomia também é um termo ambíguo, polissêmico e que é vinculado ao processo de formação neoliberal. A ação de empreender é concretamente um slogan 4 , pois, no atual sistema econômico o empreendedorismo atua como processo de validação da flexibilização de vínculos trabalhistas, mais do que propriamente como processo participativo. Já o termo polivalência, que de modo geral, diz respeito à capacidade de desenvolver multitarefas em um mesmo posto de trabalho, para o ensino de arte há um debate muito próprio e muito atual na presente legislação, em especial em relação à Base Nacional Comum Curricular (BNCC) que traz nova roupagem ao tema da polivalência, agora traduzido como "artes integradas".

Na década de 1980, a partir da Lei n. 5.692/1971, que criou os cursos de Educação Artística, foi travada uma batalha hercúlea defendendo a formação de professores de artes por área específica do conhecimento artístico. As associações de representação defendiam que o professor de Artes Visuais ministrasse aulas de Artes Visuais, que o de Música, aulas de Música e o de Teatro, da mesma forma ministrasse aula de teatro na escola. Nesse momento da disciplina Educação Artística, a formação era polivalente, um professor multitarefa que ministrava um pouco de cada conteúdo e com pouca profundidade e condições de trabalho escassas. Finalmente, nos dois últimos anos de sua formação, o estudante poderia optar por uma licenciatura plena, que habilitava para o Segundo Grau, na atualidade, denominado de Ensino Médio.

Uma luta profícua dos profissionais da área, dos intelectuais e associações construiu um novo cenário na década de 1990 em que as licenciaturas foram paulatinamente transformando-se em cursos não polivalentes, buscando desse modo sua formação plena por área. Nos primeiros anos do século XXI, essa era uma prática consolidada, mesmo que nas redes de ensino ainda existisse certa pressão para o ensino polivalente, nas universidades esse era um debate vencido em favor da qualidade e os professores de artes estavam preparados para fazê-lo nas escolas, mostrando a importância do aprofundamento em cada uma das áreas por um profissional habilitado. $\mathrm{Na}$ área de língua estrangeira, por exemplo, esse debate sobre a polivalência é inexistente. O professor com formação em francês ministra suas aulas de francês, o de espanhol, aulas de espanhol e assim por diante, não há uma atuação polivalente, ou seja, um professor de língua estrangeira não ministra inglês, francês e alemão.

No ano de 2010, a Federação de Arte Educadores do Brasil (FAEB) inicia um importante movimento para aprovação de uma lei que garantisse o fim da polivalência, embora ambígua a lei foi aprovada no ano de 2016, sob o número 13.278/2016. No entanto, passados três anos a conjuntura já não é favorável ao fim da polivalência, muito pelo contrário, a polivalência se fortalece sobremaneira no documento final da BNCC 5 .

A BNCC é um documento que, diferente dos Parâmetros Curriculares Nacionais (PCNs), tem força de lei e adentra as salas de aula de uma forma efetiva, estimulando os estados e municípios a ajustar-se

\footnotetext{
${ }^{4}$ Sobre os slogans na educação, ver Evangelista (2014).

${ }^{5}$ É preciso destacar que há um argumento econômico para a defesa da polivalência ela mantém um professor ministrando três ou quatro disciplinas ao invés de ter um profissional habilitado para cada área.
} 
ao documento nacional. A proposta pretende interferir diretamente nas matrizes curriculares, tanto das escolas, quanto das licenciaturas.

Saviani (2016) discorre sobre currículo e parte do conceito mais amplo de currículo, como o conjunto de atividades desenvolvidas na escola, para chegar na concepção de currículo como o conjunto de conhecimentos nucleares desenvolvidos no âmbito escolar. Nessa proposição, o autor diferencia os conhecimentos nucleares dos extracurriculares, aqueles que não são o cerne das ações escolares, como os eventos, datas comemorativas entre outras atividades escolares que muitas vezes tomam conta do cenário educacional. Sintetiza o autor que "Um currículo é, portanto, uma escola funcionando, isto é, uma escola desempenhando a função que lhe é própria" (SAVIANI, 2016, p. 57). Democratizar os conhecimentos produzidos socialmente pela humanidade, e na maioria das vezes apropriado unicamente pelas classes dominantes, é objetivo da escola.

O papel da escola democrática será, pois, o de viabilizar a toda a população o acesso à cultura letrada consoante o princípio que enunciei em outro trabalho (SAVIANI, 2012a) segundo o qual, para se libertar da dominação, os dominados necessitam dominar aquilo que os dominantes dominam (SAVIANI, 2016, p. 58).

Considerando a proposição do autor, de eliminar a restrição ao acesso aos conhecimentos sócio-históricos, passo a analisar o documento da BNCC na especificidade do Ensino de Arte, cujas proposições são tão amplas que pouco auxiliam o professor a desenvolver sua prática pedagógica. A parte do documento voltada para o Ensino de Arte utiliza a ideia de competência, refutada por Duarte (2008). Para o autor, tal conceito em conjunto com a pedagogia do "aprender a aprender" forma uma ampla corrente utilizada na atualidade caracterizada pelos métodos ativos que tornam o professor um facilitador do processo educacional. Esclarece Duarte que essas ideias buscam dar uma roupagem atual para o movimento Escola Nova, corrente liberal desenvolvida no Brasil no início do século XX.

Aprofundando um pouco mais sua análise Duarte (2008) mostra que, segundo Philippe Perrenoud (1999, p. 54),

[...] a formação por competências exige uma pequena 'revolução cultural' para passar de uma lógica do ensino, para uma lógica do treinamento (coaching), baseada em um postulado relativamente simples: constroem-se as competências exercitando-se em situações complexas.

Já em 2008, era possível vislumbrar que a concepção de formação por competências, tomada da lógica empresarial para a educação, introduzida por Perrenoud na educação brasileira e disseminada na BNCC, ampliaria a lógica neoliberal de desqualificar a formação na escola.

Em especial para os elementos do processo criador, em qualquer área e no Ensino de Arte em particular, o treinamento não substitui o ensino, e este por sua vez não diz respeito unicamente aos modos de aprendizagem tradicionais, ensinar pode ser transformador se as abordagens escolhidas para aprendizagem dos conteúdos forem as mais adequadas para que o estudante aprenda.

Outro aspecto crítico da BNCC é o lugar designado à arte na escola. Segundo Fonseca da Silva, Hillesheim e Ruschel (2019), na organização da BNCC, a área de Arte já tem uma perda, quando se insere na área de linguagens e se mistura com Língua Portuguesa e Língua estrangeira, e as áreas de fato transformam-se em assessórios (Música, Artes Visuais, Dança e Teatro).

Voltando aos slogans utilizados nas reformas que se sucederam ao longo dos anos de 1990, polivalência, autonomia e flexibilidade, é possível afirmar que esses elementos continuam presentes na atual BNCC. No caso das Artes, a polivalência se traduz em artes integradas. A ideia de integração 
SILVA, M. C. R. F.

curricular, que poderia sugerir trabalho de equipe entre os professores das diversas áreas (Artes Visuais, Dança, Música e Teatro), revela-se inoperante na prática do professor que, tendo formação em uma área, ministra conteúdos das demais como estratégia de integração, ou polivalência como é mais conhecido esse movimento na área de artes. Ainda é necessário demarcar que uma formação de graduação que aborde as Artes Visuais, Dança, Música e Teatro não conseguiria fazê-lo de modo aprofundado, pois cada uma delas apresenta um conjunto de conhecimentos próprios, com determinadas experiências de aprofundamento que se diferenciam umas das outras. Desse modo, esses conhecimentos aparecem na realidade de forma integrada, mas quase sempre propostos por profissionais com especificidades de formação ${ }^{6}$.

A autonomia é sempre relativa, pois resulta de relações sociais construídas em grupo, porque o professor é um ser social, assim como seus estudantes. Também a arte tem sua autonomia relativa, segundo Vazquez (1978), a arte não é um puro reflexo da realidade, mas também não é o seu contrário, completamente distanciada daquilo que é humano. Segundo o autor, "O homem se eleva, se afirma, transformando a realidade, humanizando-a, e a arte com seus produtos satisfaz essa necessidade de humanização. Por isso, não há - nem pode haver - 'arte pela arte', mas arte por e para o homem" ( VAZQUEZ,1978, p. 48). É possível dizer que a potência do processo criador humano está vinculada diretamente à transfiguração que o artista produz, a partir da humanidade que lhe é comum, construindo, como diria Vazquez (1978), uma forma peculiar de trabalho criador, a arte.

A flexibilização então é o elemento que poderia de um lado propiciar uma maleabilidade na vida social, uma capacidade de utilizar a plasticidade cognitiva, como diria Vigotski (2009); a crise do capital (IASI, 2009) e sua saída neoliberal flexibilizam as relações de trabalho, as condições da previdência, a qualidade da escola pública e da formação continuada dos professores, e a formação estética, o que impõe uma necessária hostilidade à arte. Por isso é preciso analisar as políticas educacionais de forma crítica, buscando antever nas entrelinhas o que está proposto e suas consequências.

\subsection{Contribuições do projeto Observatório da Formação em Artes Visuais}

Com o objetivo de problematizar as produções do Observatório, neste tópico apresento um conjunto de cinco dissertações de mestrado produzidas de 2012 a 2017, desenvolvidas no Programa de Pós-Graduação em Artes Visuais ${ }^{7}$, da Universidade do Estado de Santa Catarina (UDESC) e que analisam as matrizes curriculares dos cursos de Artes Visuais das Regiões Sul e Nordeste do Brasil mostrando as tendências nacionais semelhantes que conformam um modelo para as licenciaturas em Artes Visuais. Destaco, inicialmente, os estudos de Azevedo (2014), Alvarenga (2015), Müller (2017), Santos Silva (2017) e Silva (2018). Outros estudos regionais foram realizados como os de Carnevsky (2018) que investigou a Região Norte. Utilizarei dados coletados por Fonseca da Silva e Pera (2014) e Fonseca da Silva, Agostinho e Zanoni (2019). Igualmente faz parte do escopo o estudo de Hillesheim (2014) que se debruçou sobre a análise de teses e dissertações, publicadas de 2012 a 2014, existentes no Brasil sobre as licenciaturas em Artes Visuais.

Santos Silva (2017) desenvolveu seu estudo na Região Nordeste, precisamente uma análise de como os conhecimentos relativos ao ensino das tecnologias estão inseridos nas matrizes curriculares das licenciaturas em Artes Visuais na Região Nordeste. Esse estudo analisou 13 instituições públicas com cursos presenciais. Da mesma forma, dados de Alvarenga (2015) demonstram inicialmente que há poucas instituições públicas que se dedicam à formação docente em Artes Visuais no Paraná. A pesquisadora dedicou sua coleta de dados para as oito instituições públicas e presenciais existentes no estado.

A dissertação de Muller (2017) analisou cinco instituições públicas que formam professores de Artes Visuais no Rio Grande do Sul, no entanto mapeou nove entre públicas e privadas existentes.

\footnotetext{
${ }^{6}$ Sobre esse tema aprofundar em Fonseca da Silva e Alvarenga (2018).

7 Orientação de Maria Cristina da Rosa Fonseca da Silva.
} 
Alguns dos resultados encontrados nos três estudos são similares, entre eles os de Muller (2017) no que diz respeito à inserção geográfica dos cursos, de modo geral localizados no litoral e nas capitais como mencionado também no estudo de Santos Silva (2017). No caso do Rio Grande do Sul, estado analisado por Muller (2017), há um retrato de fechamento dos cursos e consequentemente regiões sem cursos de licenciatura, resultando em diminuição do quantitativo de instituições para a formação em Artes Visuais. Uma consequência de "litoralização" da formação é que as empresas privadas que ofertam cursos na modalidade a distância conquistam um farto quinhão da formação de professores no interior dos estados.

Há também estudos específicos sobre o estado de Santa Catarina, entre eles Fonseca da Silva e Pera (2014) e Fonseca da Silva, Agostinho e Zanoni (2019). O primeiro mapeia as especificidades da oferta de instituições de ensino superior (IES) do Sistema Acafe ${ }^{8}$, analisando questionários enviados aos coordenadores de curso que apontam as dificuldades de expansão e manutenção no interior do estado, a pequena oferta de pesquisa, escassez de bolsas e a inexistência de pós-graduação na área de Artes Visuais, é uma constante na fala dos entrevistados. O único curso existente hoje em Santa Catarina é a Pós-Graduação em Artes Visuais da UDESC que conta com mestrado e doutorado.

Ainda sobre Santa Catarina um dado secundário que aparece nos estudos realizados, diz respeito à oferta da Educação a Distância (EaD), que como pode ser vista nos mapas a seguir, disputa com as demais IES a formação de professores de Artes Visuais principalmente no interior do estado. Embora não seja o recorte para este texto, é um elemento que tem causado preocupação no que diz respeito à qualidade da oferta de formação por redes privadas. Formulo o cenário da oferta de EAD em Santa Catarina com maior detalhe em Fonseca da Silva (2017).

Figura 3 - Mapa licenciaturas na modalidade presencial

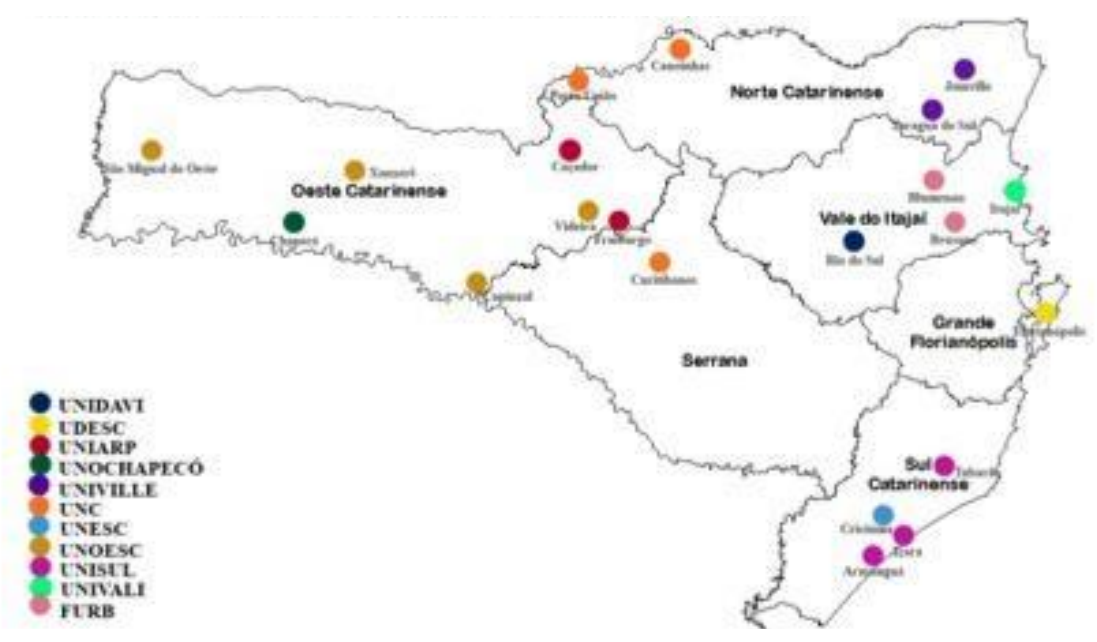

Fonte: Fonseca da Silva (2017)

\footnotetext{
${ }^{8}$ Sistema que reúne universidades públicas de direito privado em Santa Catarina. Compõe o sistema de ensino superior do estado. A UDESC participa da associação, mas é pública e gratuita e a UFSC não participa da associação.
} 
Figura 4 - Mapa Licenciaturas na modalidade EAD

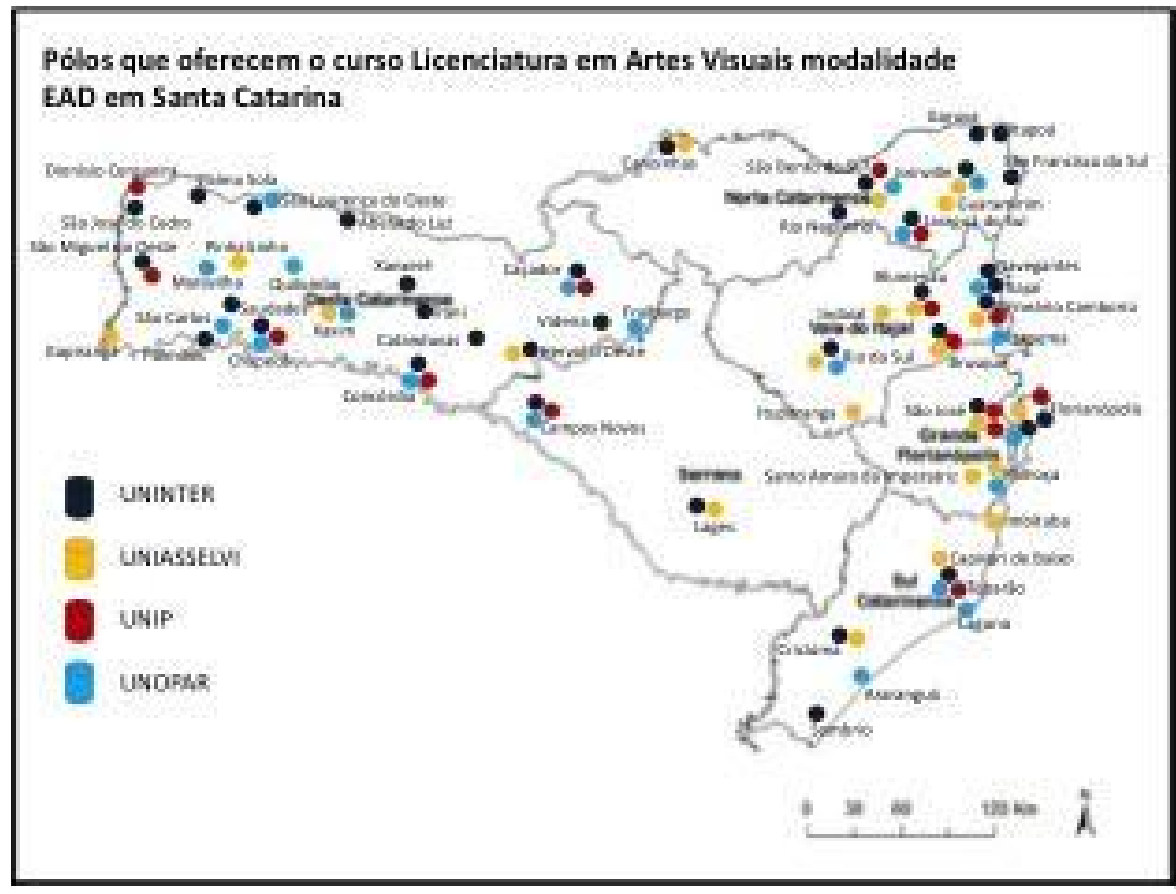

Fonte: Fonseca da Silva (2017)

Outros estudos do Observatório analisam os projetos curriculares em outros estados. Alvarenga (2015) investigou os cursos de licenciatura em Artes Visuais do Paraná, seu objeto foi as políticas educacionais e sua influência nas licenciaturas, sua análise sobre as disciplinas, assim como a de Silva Santos (2017), se debruça sobre os conhecimentos relativos ao ensino das tecnologias, como, esses conteúdos estão inseridos nas matrizes curriculares das licenciaturas em Artes Visuais. Ressalta-se que no caso de Alvarenga (2015) a análise é realizada com foco no desdobramento de políticas educacionais e suas reverberações na formação nas licenciaturas em Artes Visuais. A autora pautou em seu estudo três aspectos vinculados com políticas educacionais, referente às tecnologias contemporâneas; observadas nas diretrizes para as Artes Visuais e também nas diretrizes para a Educação Básica, referência à Lei n. 11.645/2008 (História e Cultura Afro-Brasileira e Indígena) e referência à Lei n. 10.436/2002 (LIBRAS) e inclusão de pessoas com deficiência. Nesse cenário, a autora analisou o Projeto Político Pedagógico (PPP) de oito instituições públicas do Paraná para identificar o cumprimento dessas políticas. No resumo apresentado a autora destaca que:

[...] todas as IES analisadas oferecem disciplinas contemplando as tecnologias contemporâneas, o que demonstra sua preocupação com a produção artística atual. No entanto, nem todas as IES analisadas ofertam disciplinas abordando a História e Cultura Afro-Brasileira e Indígena ou Libras e inclusão de pessoas com deficiência, sendo que existem leis sobre esses últimos pontos, além da recomendação nas DCNs - Artes Visuais e nas DCNs da formação de professores da educação básica (ALVARENGA, 2015, p. 6).

Seria necessário fazer uma análise mais específica sobre as características político-sociais do estado, formação cultural e política para identificar as dificuldades de implementação das diretrizes étnico-raciais. Alvarenga (2015) aponta que mesmo que mais de $50 \%$ das instituições tenham atingindo a meta de inserção das tecnologias, o mesmo não se observa em relação às outras políticas.

Em comparação ao estudo de Santos Silva (2017) que analisou o movimento cultural de sua região como pano de fundo da análise curricular e identificou o relativismo cultural como um pressuposto da 
maioria dos currículos, talvez embora a Região Sul e a Nordeste estejam distanciadas geograficamente o modus operandi curricular tem pontos de encontro, pois ambos estão ligados a uma mesma política educacional. A autora cria um conceito de "currículo-mucambo", definindo-o:

[...] como sendo aqueles currículos que estruturam conteúdos e práticas pedagógicas que desconsideram as contradições postas nos discursos, imagens, textos e, inclusive na própria história social do nordeste (SANTOS SILVA, 2017, p. 223).

A análise da autora constata a criação de uma narrativa do Nordeste regionalista ou de inferiorização em relação ao contexto nacional que também margeia o currículo. $O$ apagamento das referências à cultura indígena e à africana nos currículos do Paraná pode ter também como origem as contradições entre o embranquecimento da população e a soberania dos conteúdos europeus e norte-americanos nas ementas de disciplinas.

Em relação ao Nordeste, a autora destaca que o problema da região não é a seca, é o latifúndio. A seca é um pretexto de captação de recurso e de isolamento político na perspectiva da maioria da população.

Santos Silva (2017) também aponta que, da análise dos PPPs, somente 31\% abarcam os temas regionais e locais. A prática social local que envolve os estudantes é pouco utilizada como ponto de partida para a aprendizagem dos conteúdos basilares, ou seja, aqueles conteúdos fundantes da aprendizagem, são deixados para segundo plano.

No levantamento da oferta de disciplinas que abordem as tecnologias, o estudo de Santos Silva (2017) destaca que nos projetos analisados há oferecimento de oito disciplinas em sete instituições, ao mesmo tempo em que denota que essa oferta alicerça poucos componentes críticos-reflexivos e ou pedagógicos para a prática docente na escola. Diferentemente, a autora encontrou "Cinquenta e sete componentes curriculares que apresentam abordagens técnicas, historicistas, ou de processos de criação no uso das ferramentas tecnológicas" (SANTOS SILVA, 2017, p. 228), ou seja, há uma predominância da formação para o uso das tecnologias na formação do professor de arte. Os dados apresentam uma dicotomia entre o uso pedagógico das tecnologias e o uso destas como ferramenta ou linguagem para a produção artística, reafirmando uma contradição presente na história do Ensino de Arte no Brasil entre quem produz e quem ensina arte na escola.

O estudo de Santos Silva (2017) também disponibiliza resultados para pensar a formação de professores de arte, entre eles, a necessidade de reforçar os conhecimentos basilares e de romper a lógica reprodutora do discurso acrítico hegemônico. Reafirma a necessidade de ações que combatam a precarização da formação. Assim como Alvarenga (2015), a autora também constata a influência dos documentos regulatórios no currículo, são estes que movem as reformas curriculares.

Outros dois estudos desenvolvidos por Silva (2018) e Azevedo (2014) abordam duas realidades distintas. O primeiro dedica-se a investigar o curso de formação em Artes Visuais na cidade de Parintins, na Amazônia. Analisa como o curso, que é fruto da política pública de expansão da interiorização da formação ${ }^{9}$, se situa em uma região de difícil acesso e com poucos recursos para superar a sua condição geográfica. Nesse caso, a escassez de corpo docente efetivo bem como de possibilidades de afastamento para formação continuada se colocam como alguns dos desafios postos.

\footnotetext{
9 Programa de Apoio a Planos de Reestruturação e Expansão das Universidades Federais (REUNI), programa instituído pelo Governo Federal na gestão do Governo de Luiz Inácio Lula da Silva por meio do Decreto 6.096, de 24 de abril de 2007.
} 
Há também influência das questões locais como a indústria do Boi Bumbá que justificaram a criação do curso de Licenciatura em Artes Visuais na cidade de Parintins, no interior do Amazonas. As atividades do Boi ao mesmo tempo em que interferem na proposta pedagógica do curso, uma vez que há uma demanda dos estudantes por enfoque demasiado na atividade de produção das festividades do boi, também é a forma de subsistência econômica dos estudantes. Ressalto aqui as contradições entre a produção local e os conhecimentos sócio-históricos distribuídos no processo educacional.

O estudo de Azevedo (2014) amplia o âmbito de atuação do Observatório no Brasil e inicia a reflexão sobre as relações entre Brasil e Argentina fortalecendo os objetivos iniciais do Observatório no que diz respeito à análise da oferta de disciplinas que problematizem o tema da América Latina. Igualmente destaco dois aspecto, o primeiro diz respeito à escassez de disciplinas nos cursos brasileiros de três universidades púbicas que se dedicam a estudar a América Latina. $O$ segundo aspecto que incita reflexão, e que interfere em sala de aula, diz respeito a quais os conteúdos são selecionados para abordar a teoria e história da arte no Brasil?

Qual o espaço da arte branca, europeia e produzida por homens em detrimento da produção latino-americana, ameríndia e produzida pelas mulheres no currículo escolar? Observo que os dois aspectos interferem na formulação do currículo da escola básica.

Certamente fiz uma síntese das muitas questões postas nos estudos do Observatório, em especial as que orbitam no PPGAV/UDESC. Alguns estudos em marcha apontam a necessidade de mergulhar em temas mais específicos, como o tema da tese de Perini (2017), que aprofunda a análise sobre os aspectos referentes ao estudo da cultura negra na matriz curricular dos cursos de Artes Visuais no Maranhão. Ou mesmo o estudo de Valéria Alvarenga ${ }^{10}$ que se reporta à Argentina, buscando mapear as contribuições dos colegas pesquisadores desse país, desenvolvendo trocas entre duas realidades tão próximas e ao mesmo tempo tão separadas em termos de pesquisa científica acerca da formação em Artes e suas políticas educacionais.

As políticas educacionais são por vezes resultado da disputa entre movimentos sociais e governo, interesses privatistas e educação pública apontando o movimento social de cada época. Nesse caso, o Estado de modo geral atua no sentido de defender os interesses do capitalismo. Principalmente no momento em que o Brasil vive a situação de disputa da Educação pública, em especial no Ensino da Arte, a conjuntura política imputa importantes derrotas, haja vista a implementação da nova BNCC e o corte paulatino de recursos da Educação pública. Com esse pano de fundo, um tanto recortado por diferentes conjunturas políticas e governamentais ${ }^{11}$, pretendo no próximo tópico apontar considerações acerca do quadro atual da oferta de artes na escola e mesmo identificando derrotas que nos levam de volta para os anos de 1980, propicia momentos de crescimento político e nos anima a criar novas formas de resistência.

\section{QUADRO ATUAL DA OFERTA DE ARTES NAS ESCOLAS}

Ao analisar as relações dos tópicos anteriores com o Ensino de Artes Visuais na Escola, busco extrair elementos para uma análise mais aprofundada do Ensino de Arte nas escolas públicas diante das atuais políticas. É preciso perguntar: quais as contribuições dos estudos que tomam as licenciaturas como objeto de estudo? Como essas investigações podem contribuir para o ensino de artes nas escolas? A primeira contribuição é identificar o modelo de formação que é disseminado na atualidade e quais as consequências para a escola. Vamos tomar aqui a ideia de modelo, não como algo fechado, acabado, mas como um elemento aglutinador de políticas que vai guiando o processo e conformando um caminho hegemônico tanto para a formação docente, quanto para a educação escolar. Esses modelos de modo geral são mediados por disputas entre setor hegemônico e setor crítico, inclusive inserindo

\footnotetext{
${ }^{10}$ Concepções de arte presentes nas pesquisas sobre formação docente em artes visuais no Brasil e na Argentina. .

"Esses cenários são permeados por movimentos políticos nacionais e internacionais que agem associados para ampliar os ganhos dos capitalistas principalmente em países pobres e dependentes.
} 
aspectos defendidos pelos setores críticos a fim de criar um pertencimento entre os docentes, para que estes tenham adesão com as novas propostas ditas inovadoras. Nesses casos, a política educacional produz um engodo criando a sensação de que os governantes estão de fato querendo colocar a educação a frente dos interesses do capitalismo. Desse modo, como é possível ver, há a política pública, mas não há o investimento necessário. Tomei a ideia de modelo de formação docente para caracterizar procedimentos comuns, para organizar de forma didática a exposição das características disponíveis para descrição nos estudos e documentos disponíveis.

O modelo de formação nas licenciaturas atende as demandas das Diretrizes Curriculares para o Ensino das Artes Visuais (2009), a análise das matrizes curriculares pelo Observatório destaca que embora as reformas demorem para ser realizadas, elas consideram a expectativa dos documentos governamentais, pois quando o documento é disponibilizado já foi construído uma ambientação para ele, muitos slogans presentes já foram disseminados. Na atualidade, há uma gama de documentos que precisam por força da lei ser considerada no PPP dos cursos de licenciatura. De modo geral as novas e as velhas práticas convivem nos cursos e há uma semelhança de PPPs entre as Regiões Norte e Sul.

Outro dado analisado é que a organização dos cursos mesclam conteúdos chamados clássicos com práticas tradicionais e conteúdos que buscam romper com essa lógica, mas que trazem pouca sustentação. Nesse modelo o estudante em formação perde a base do modelo "belas artes" que atravessou séculos e no seu lugar apresenta-se um esvaziamento dos conhecimentos por meio de metodologias ativas sem as condições necessárias para sua absorção.

Para aprofundar essa análise vou apresentar três modelos de formação de professores de Artes Visuais que reverberam na educação escolar: o primeiro, que vou chamar de modelo belas artes, o segundo, de modelo construtivista e o terceiro, de sócio-histórico. No primeiro modelo, a prática é o fator que baliza o conhecimento, a aprendizagem relevante se dá no processo de construção do fazer artístico, há uma nítida divisão entre teoria e prática, as disciplinas de teoria e história da arte são ministradas no formato enciclopédico e os conteúdos preponderantes dizem respeito aos temas da arte branca, europeia e norte-americana, bem como a arte produzida por homens. O ensino é um apêndice na formação do licenciado e os bacharelados são carreiras distintas que em algumas instituições fizeram parte do modelo $3+1^{12}$. Nesse modelo, a formação do artista é o ponto alto, mas poderá também ter um desdobramento para a formação do professor de Educação Básica, do professor universitário, do pesquisador, ou mesmo do historiador da arte.

No segundo modelo, há uma flexibilização, as fronteiras se dissipam e a virada educacional (GONÇALVES, 2011) traz o artista como o protagonista da formação, o modelo de organização do currículo por oficinas, recebe menos adeptos, embora algumas das oficinas permaneçam, mas já com o artista como elemento central da formação. As contribuições das perspectivas conceituais da arte contemporânea vão permear a formação que estou chamando de construtivista ${ }^{13}$. Nessa abordagem, há um espaço maior para artistas mulheres e grupos étnicos diferenciados. Como aponta Duarte (2000), o construtivismo vai servir de elemento aglutinador das correntes liberais e pós-modernas. Esse modelo dá ao professor o status de facilitador da aprendizagem e os métodos ativos recebem espaço na atuação docente.

Nesse novo modelo, as ideias do multiculturalismo, do ativismo a partir da arte, a sobreposição da cultura visual sobre a teoria e história da arte é uma constante. Os pressupostos têm como objetivo sobrepor o formato tradicional de Ensino de Teoria e História da Arte. Nessa nova abordagem, graças à

\footnotetext{
${ }^{12}$ Em ambos os casos vigorava o mesmo esquema: três anos para o estudo das disciplinas específicas, vale dizer, os conteúdos cognitivos ou "os cursos de matérias", na expressão de Anísio Teixeira, e um ano para a formação didática (SAVIANI, 2009).

${ }^{13}$ Incorporo nesse modelo as críticas ao "ao aprender a aprender" e as apropriações neoliberais e pós-modernas da teoria de Vigotski apontadas por Duarte (2004).
} 
SILVA, M. C. R. F.

flexibilização do currículo há uma perda de conteúdos para a formação de professores que se unifica com uma conjuntura hostil ao trabalhador da educação profissionalmente precarizado. Por outro lado, nessa mesma abordagem há uma concepção inclusiva a partir da inserção de grupos excluídos da história da arte tradicional como as mulheres, os negros e os indígenas e o debate acerca das questões mais amplas de gênero. Há que se considerar que mesmo com essa inclusão pedagógica de artistas, movimentos, ativistas na formação inicial dos professores, esta perspectiva construtivista pouco tem contribuído para uma ampliação da formação política dos professores e seus alunos, pois essas mudanças se sustentaram na filosofia e nas ideologias pós-modernas que não foram capazes de fazer uma crítica estrutural ao capitalismo. Também, os processos de exclusão no campo da arte reverberam de forma muito tímida na organização do segmento educacional, ou mesmo para a compreensão da exclusão/inclusão de grupos políticos e artístico-culturais como estratégia de manutenção do capitalismo cultural (JAMESON, 1997).

Já no terceiro modelo de caráter sócio-histórico, a formação se dá a partir de categorias que debatem as necessidades estéticas dos sujeitos, sua produção, consumo e disseminação como produto histórico e síntese de múltiplas determinações. Não é desejável o apartamento entre teoria e prática e o currículo não é um conjunto de etapas que se organizam por movimentos lineares, ao contrário pretende-se selecionar os conhecimentos mais relevantes no campo da arte para a libertação das condições de opressão postas no capitalismo. Fundamentado em Saviani (2007), o ponto de partida é a prática social inicial e num movimento orgânico a prática social transformada é o ponto de chegada ao final de um ciclo de aprendizagem ${ }^{14}$.

Fortalecer as possibilidades de ampliação da consciência sócio-histórica, de modo que os professores em formação possam problematizar a produção histórica desses fenômenos e de como a arte se engendra na produção de diferentes tempos sociais. Por outro lado, o professor de arte é visto como um sujeito de direitos, um intelectual transformador que necessita um conjunto de dimensões amalgamadas do conhecimento artístico para atuar na realidade escolar.

Os modos de produção da história, podem ser levados em consideração como elementos capitalizadores dos planejamentos pedagógicos a partir de uma perspectiva de educação crítica. Na concepção de Saviani (2007) a escola pública tem o compromisso de lutar pelo fim da marginalidade na América Latina. Nessa abordagem, é fundamental diferenciar o conceito de universalidade de uso no senso comum com o conceito de universalidade utilizado no campo do materialismo histórico dialético. Para o primeiro o universal diz respeito a um campo amplo de conhecimento entendido como "história universal da arte", um conhecimento enciclopédico dado como uma verdade. Já a segunda posição entende o universal como algo que pode ser apropriado por todos, por exemplo, o acesso à educação pública como um direito universal de todos.

A escola, por sua vez, recebe no atual governo novos ataques: da "escola sem partido" 15 " e uma constante perseguição dos professores, dos cortes de recursos, dos cortes na formação em cursos de pós-graduação. A produção cotidiana da desqualificação dos professores é a tônica, pois as políticas extrativistas dos governos neoliberais transformam a educação em mercadoria, explorando a escola em todas as suas dimensões. Por meio dos insumos (livros, cartilhas, jogos, objetos), por meio das tecnologias (equipamentos, software, vídeos, lousas digitais, ambientes virtuais), como também há uma expropriação dos conteúdos na formação de professores e no desenvolvimento da atividade profissional (formação a distância, planos de previdência, cursos e assessorias privadas). De modo geral,

\footnotetext{
${ }^{14}$ Sobre esse tema ver também: Marsiglia, Martins e Lavoura (2019).

${ }^{15}$ Projetos de lei, com diferentes formatos, apresentados com o objetivo de atribuir aos professores a responsabilidade sobre a doutrinação ideológica.
} 
as instituições privadas ${ }^{16}$ têm se imiscuído no aparelho estatal, no entanto o fazem com pouco ou quase nenhum acúmulo de trabalho na área educacional.

Os desdobramentos do modelo de formação belas artes e do construtivista convivem na escola, mesclando práticas e reflexões. Já o modelo sócio-histórico até o momento não encontrou de forma ampla as condições necessárias para sua implantação integral, dados os limites de uma posição sócio-histórica no capitalismo. Portanto, suas ideias são encontradas presentes em documentos e manifestos, bem como experiências desenvolvidas em diferentes contextos, redes municipais, estaduais, escolas e universidades, na pedagogia da alternância e nas pedagogias socialistas de modo geral. Há também um conjunto de processos e de práticas pedagógicas que vêm sendo sistematizadas por vários educadores no área de pedagogia, das licenciaturas, mas pouco tem sido produzido na área de $\operatorname{arte}^{17}$.

A disciplina de arte na escola de Ensino Fundamental é ministrada de diferentes formas, em algumas redes desde a Educação Infantil, em outras nos primeiros anos do Ensino Fundamental, ou mesmo somente nas séries finais. Já, no Ensino Médio, a oferta de arte tem sido ameaçada a partir da aprovação da BNCC, por outro lado a $\mathrm{FAEB}^{18}$ tem atuado firmemente na defesa do Ensino de Arte nas Escolas.

Algumas redes também oferecem mais de uma área do ensino de arte na escola (Artes Visuais, Dança, Música, Teatro), mas ainda é raro esse formato.

Também é perceptível a necessidade de professores com formação na área, pois os dados levantados pelo Observatório apontam um número muito exíguo de docentes com formação atuando na rede educacional. No caso de Santa Catarina, por exemplo, Hillesheim (2018) destaca que somente $26 \%$ dos professores que atuam no Ensino de Artes no estado têm formação completa em artes.

As políticas educacionais existentes não dão conta de ampliar a qualidade da formação de professores de Artes, primeiro porque o Estado não está comprometido com os interesses da maioria da população, depois porque não há investimento adequado nem nas universidades públicas, nem nas escolas, fato que precariza a formação de modo geral.

Igualmente os slogans educacionais também disseminam proposições para a Educação Básica que auxiliam a culpabilização dos estudantes, das famílias, dos professores da Educação Básica e mais recentemente os grandes vilões são as universidades públicas.

Alguns aspectos como qualificação e investimento, que seriam fundamentais para um Ensino de Arte que contribua para a humanização, vêm perdendo espaço a partir dos cortes de verbas, ou mesmo da formação aligeirada. Pouco investimento na materialidade do trabalho do professor de artes como salas adequadas com piso cerâmico, tanque, materiais e papéis variados estão presentes nas escolas públicas. Bibliotecas com livros de artes, imagens, vídeos e computadores de qualidade também fazem parte dessa realidade. Máquinas fotográficas e filmadoras igualmente contribuem para uma melhor rotina de trabalho do professor. Toda espécie de oportunidade de ampliar o repertório dos estudantes colabora para o ensino de arte de qualidade. Os espaços culturais, o contato com artistas locais, museus, museus virtuais, também favorecem a ampliação da formação dos estudantes. Do mesmo

\footnotetext{
${ }^{16}$ Como exemplo: Cursos a distância do Instituto Natura, disponível em: <http://www.institutonatura.org.br/blog/acoes-professores-cursos-distancia-do-instituto-natura/>. Acesso em: 27 maio 2019.

${ }^{17} \mathrm{O}$ Grupo de pesquisa Educação, Artes e Inclusão tem atuado nessa perspectiva, assim como uma parcela de pesquisadores vinculados ao Observatório da Formação de Professores no âmbito do Ensino de Artes.

${ }^{18}$ Federação de Arte-Educadores do Brasil - FAEB
} 
SILVA, M. C. R. F.

modo, é possível dizer que um conjunto amplo de professores de arte fazem um trabalho adequado, mesmo diante de uma realidade de escassez, mas não pode recair sobre este, o sucesso/insucesso pela formação de legiões de estudantes.

Já em relação à formação aligeirada, cada dia amplia-se o número de cursos que oferecem formação de graduação em cursos que tenham em vista a formação crítica do professor de arte, capaz de intervir no cenário escolar coletivamente. Nesse sentido nossa crítica se refere especialmente à rede privada de EaD. No caso do curso de Artes Visuais que necessita de espaços de práticas, a precarização da formação é ainda maior, afastando a oportunidade dos estudantes de conhecer e experimentar a arte que é produzida além do seu entorno. De todo modo, a formação do professor de arte, com repertório conceitual, político, cultural, teórico-prático é a chave para a qualificação do ensino de arte na escola. Tanto os cursos de graduação quanto as escolas precisam ampliar as formas de aprender, estudar, investigar, conhecer e produzir arte na escola. O Estado tem seu papel de investidor nesse cenário, inclusive ampliando a prioridade do ensino de arte nas escolas. É emergente o fim da percepção da Educação Estética ${ }^{19}$ como enfeite no currículo, como apêndice, há que colocá-la na centralidade apostando em sua função socio-humanizadora.

Experiências como p Programa Institucional de Bolsas de Iniciação à Docência (Pibid) e Residência Pedagógica, que sofreram cortes tanto no modelo quanto de recursos financeiros do seu projeto inicial, poderiam ampliar a qualificação da formação docente. No entanto, os entes governamentais agem na contramão e minimizam os programas quando deveriam ampliá-los e fortalecê-los.

Compartilho uma análise já posta por Fonseca da Silva, Schlichta e Hillesheim (2019), mas que reaparece no presente texto sobre novo contexto que analisa um novo slogan presente no pensamento pós-moderno e que amplia as atribuições dos professores de artes: o professor-pesquisador e o professor-artista. Por que não basta ser professor de Artes Visuais? Por que o sujeito precisa ser professor-pesquisador e professor-artista?

Para refletir sobre as perguntas pontuarei alguns aspectos: primeiramente dizer que a profissão de professor atravessa dificuldades históricas, inclusive ampliadas a partir da universalização da educação pública no Brasil por volta de 1940, quando a educação estatal passa a ser expandida para todos os estudantes em idade escolar. Naquele momento, a profissionalização inicia seu processo de precarização, pois os recursos não acompanham as necessidades de ampliação do sistema. A luta por mais condições e maior valorização da profissão cria no ideário político-pedagógico do professor a necessidade de visibilizar atributos que validem a profissão socialmente. Nessa ampliação dos atributos, há também o alargamento das tarefas e, portanto, não basta mais ser professor, é preciso ser também pesquisador e, posteriormente, artista. Nada contra aqueles profissionais que atuam no eixo pesquisador-artista por desejo, por afinidade. O problema que está embutido é a ampliação das condições de precarização quando a pressão por atuar nessa tríade (professor, pesquisador, artista), é mais um elemento de exploração do professor, este de modo geral não tem as condições básicas para atuar como professor, que dirá como pesquisador e ou como artista. Nesse caso, tanto o professor-pesquisador quanto o professor-artista são papéis atribuídos ao professor de arte como elemento de inovação, de atualização profissional, mas que acaba de fato imputando novas tarefas, há, aí uma homogeneização de perspectivas pós-modernas e tecnologizantes na formação docente. ${ }^{20}$

\section{CONSIDERAÇÕES FINAIS}

\footnotetext{
${ }^{19}$ Hussak e Vladimir (2011), apresentam em uma coletânea vários estudos acerda da Educação Estética. Mas de modo geral na escola há uma visão de estética como sinônimo de belo, que por sua vez carrega um sentido elitista. Nossos estudos contribuem fundamentalmente para a superação dessa visão.

${ }^{20}$ Para aprofundar o tema, ver Duarte (2010).
} 
Este artigo é produzido em um contexto de mudanças abruptas no cenário educacional brasileiro. De um lado a aprovação das $\mathrm{BNCCs}^{21}$ que, na contramão do movimento das entidades em defesa da educação, flexibiliza e empobrece a formação dos estudantes brasileiros e de outro, a vigência da Lei n. 13.278/2016, que define como linguagens do ensino de arte a Música, Teatro, Artes Visuais e Dança e também a contratação de professores conforme a necessidade. Há então duas correntes de análise da referida lei, uma que entende que a lei só estabeleceu de fato a polivalência, conforme o texto:

$\S 6^{\circ}$ As artes visuais, a dança, a música e o teatro são as linguagens que constituirão o componente curricular de que trata o $\S 2^{\circ}$ deste artigo. [...]

Art. $2^{\circ} \mathrm{O}$ prazo para que os sistemas de ensino implantem as mudanças decorrentes desta Lei, incluída a necessária e adequada formação dos respectivos professores em número suficiente para atuar na educação básica, é de cinco anos (BRASIL, 2016).

A segunda posição entende que estimula uma data para a efetiva formação e contratação de professores em cada uma das linguagens, acabando de vez com a polivalência. Outro fato inusitado é que no texto da Lei de Diretrizes e Bases não há menção à Lei n. 13.278/2016, talvez tenha passado desapercebidamente aos legisladores a existência da referida lei, ou mesmo de sua eficácia diante do projeto polivalente.

No fechamento do presente texto aponto um conjunto de considerações, que embora busquem finalizar as análises aqui propostas, não desconsideram sua provisoriedade diante do desgoverno ao qual o Brasil foi entregue nas últimas eleições. Desse modo, não há aqui a intenção de concluir, muito pelo contrário, o que pretendo é estimular o debate sobre as considerações que estamos produzindo como pesquisadores do projeto Observatório, e com todos os leitores que se aproximam.

Mais uma vez nos referimos aos fios tecidos na figura 1, por representar a necessidade de, fio, por fio compreender quais as condições que produziram o cenário presente. $\mathrm{E}$ ao mesmo tempo, como referencia a imagem da figura 2, compreender que é preciso produzir análises para além do contexto brasileiro, inclusive identificando amarrações conservadoras internacionais, sendo o Brasil, mais uma peça a serviço do capital.

Para atingir o objetivo de mostrar as contribuições do projeto em rede Observatório, é preciso dizer que um âmbito da pesquisa é político, pois a experiência social do pesquisador fortalece a organização e análise dos dados. Tenho, desse modo, a escola pública e os interesses da classe social que as frequentam como fio condutor da minha prática social, portanto da minha atuação como pesquisadora. Por outro lado, há igualmente um rigor técnico em buscar as melhores formas de desenvolvimento da pesquisa, de organização e análise, de explicitação das metodologias e de construção de um corpo teórico-prático aprofundado.

Investigando as teses e dissertações produzidas pelo Observatório já pontuadas neste texto, analiso que, em comparação com as políticas educacionais vigentes, é possível dizer que os documentos restringem a autonomia intelectual do professor e, mesmo quando apontam indícios de avanços, não contam com os recursos humanos, materiais e financeiros adequados para sua implementação. Observa-se um crescimento das práticas formativas com modelos aligeirados de formação que, ora, guardam formatos de academia, pautadas no modelo belas artes e, ora, apresentam modelos acríticos que secundarizam a atuação dos professores e privilegiam os processos de autoaprendizagem e livre

\footnotetext{
${ }^{21}$ O Parecer 7/2019 e Projeto de Resolução que altera o artigo 22. São peças importantes para entender o contexto de mudanças das matrizes curriculares das licenciaturas face ao documento aprovado da BNCC, mas a análise desse recorte exigiria outro artigo, assim nos limitamos apenas a citar tais documentos.
} 
expressão. Essas novas abordagens trazem traços da educação liberal e confundem liberdade com abandono.

Há pouco espaço nas licenciaturas para a construção de professores como intelectuais transformadores. Embora seus participantes enfatizem a defesa da arte e sua relação intrínseca com a vida, parece-nos que o sujeito social está distanciado dessa relação. É possível perceber que esses novos modelos de formação crescem em um momento que se amplia a precarização do professor que atua no Ensino Superior, assim como uma separação entre teoria e prática.

No programa em rede Observatório foi produzida uma ampla coleta de dados nas Regiões Sul, Norte, Nordeste e Centro-Oeste. Na Região Sudeste, embora existam estudos coordenados por Isabela Frade e Gerda Foerste, ainda não há um levantamento das matrizes curriculares e PPPs desses estados publicados, pois as autoras se debruçaram sobre outros objetos de pesquisa análogos ao tema da formação. Os estudos das regiões brasileiras, alvo das investigações do Observatório, trazem aspectos próprios e locais advindos da organização cultural da região. Um exemplo é a perspectiva dos estudos de Santos Silva (2017) já mencionado. Para a autora é preciso ir além dos estereótipos regionalistas, ampliando a relação do sujeito com o todo, construindo uma relação dialética entre o universal e o particular. Esses elementos de singularidade regional são parte do processo de análise sócio-histórica desse lugar e que, portanto, influenciam não só o currículo, como também as pessoas que orbitam em volta dele. No entanto, o entendimento é de que são pontos de partida, mas que a educação precisa ir além deles.

As análises produzidas nos estudos de Alvarenga (2015) e Santos Silva (2017) apresentam também uma dicotomia entre o uso pedagógico das tecnologias e o uso destas como ferramenta ou linguagem para a produção artística. As autoras reafirmam a existência de uma contradição presente na história do ensino de arte no Brasil entre quem produz e quem ensina arte na escola. Essa oposição produz um eterno embate entre a tentativa de qualificar a ação do professor e a luta por inserir o artista no sistema das artes.

Ressalto que as políticas influenciam sim a organização dos PPPs, trazem conceitos para serem operacionalizados nos cursos de formação, reformulam princípios, definem conteúdos como no caso das diretrizes étnico raciais e da Lei n. 11.645, de 10 março de 2008. Mas também tornam lei os slogans produzidos como orientadores de princípios neoliberais, mas que, traduzidos como avançados: "Educação para todos", por exemplo, liberaliza o acesso e a distribuição de recursos, flexibiliza a formação e a carreira docente e pauperizam a oferta de ensino na escola.

Uma vez influenciando o currículo das licenciaturas, as políticas educacionais desdobram-se para a escola imiscuída no processo pedagógico e na práxis docente. Também produzem embates, pois ressaltam as mudanças necessárias que não são atendidas. A entrada de alunos cotistas na universidade, as demandas desse grupo, as questões de gênero e as necessidades tecnológicas produzidas no capitalismo para gerar consumo e dependência, criam um conjunto de prioridades e embates entre formação, Artes Visuais e Educação.

Outro aspecto, não menos importante, diz respeito ao isolamento dos professores de arte na escola, detentores de carga horária pequena precisam ministrar aulas em muitas turmas para atingir o mínimo exigido de carga horária obrigatória conforme cada contrato de trabalho. Duas aulas por turma de modo geral atingem todas as classes da escola, não havendo lugar para mais de um professor e, dessa forma, quase não tem colegas da mesma área para dialogar, estudar e criar resistência, nas especificidades do ensino de artes. Essa realidade precisa de um olhar mais aproximado por parte das associações da área de Artes.

Finalmente, nossos estudos, no Observatório, pretendem organizar os dados sobre as licenciaturas e também produzir uma análise contínua das políticas educacionais que ampliem o conhecimento sobre a área e que ao mesmo tempo possam ser instrumentos de discussão sobre a 
ISSN $1983-1579$

Doi: 10.22478/ufpb.1983-1579.2019v12n3.46151

http://periodicos.ufpb.br/ojs2/index.php

formação inicial, pois, é possível observar a necessidade de estudos longitudinais, isto é, uma necessidade de continuidade que possa ao mesmo tempo subsidiar as lutas coletivas à enfrentar, atuando diariamente como professores de arte na escola e na universidade.

\section{REFERÊNCIAS}

AZEVEDO. Isadora Gonçalves. O lugar da América Latina na formação inicial de professores de artes visuais no Brasil e na Argentina. 2014. 137f. Dissertação (Mestrado) - Programa de Pós-Graduação em Artes Visuais, Universidade do Estado de Santa Catarina, Florianópolis, 2014.

ALVARENGA, Valéria Metroski de. Formação inicial do professor de artes visuais: reflexões sobre os cursos de licenciatura no Estado do Paraná. 2015. 256 f. Dissertação (Mestrado em Artes Visuais) - Programa de Pós-Graduação em Artes Visuais, Universidade do Estado de Santa Catarina, Florianópolis, 2015.

BRASIL. Lei n. 11.645, de 10 março de 2008. Altera a Lei 9.394, de 20 de dezembro de 1996, Modificada pela lei 10.639, de 9 de janeiro de 2003, Que estabelece as Diretrizes e Bases da Educação Nacional, para Incluir no Currículo Oficial da Rede de Ensino a Obrigatoriedade da Temática "Historia e Cultura Afro-Brasileira e Indígena. Disponível em: <http://legis.senado.leg.br/norma/569484>. Acesso em: 27 maio 2019.

. Lei n. 13.278/2016. Altera o $\S 6^{\circ}$ do art. 26 da Lei $n^{\circ} 9.394$, de 20 de dezembro de 1996, que fixa as diretrizes e bases da educação nacional, referente ao ensino da arte. Disponível em:

<http://www.planalto.gov.br/ccivil_03/_ato2015-2018/2016/lei//13278.htm>. Acesso em: 27 maio 2019.

CANTON, Kátia. Novíssima arte brasileira: um guia de tendências. São Paulo: Editora Iluminuras, 2001.

COSTA, Maria Luiza Calim de Carvalho. O mapa de ponta-cabeça. WORLD CONGRESS OF COMMUNICATIONS AND ARTS, 1., Proceedings..., p. 193-197, 2011.

CARNEVSKIS, Claudia. Formação de professores de artes visuais nas universidades públicas da Região Norte: cultura e arte no currículo das licenciaturas. 2018. Tese (Doutorado em Artes Visuais) - Programa de Pós-Graduação em Artes Visuais, Universidade do Estado de Santa Catarina, Florianópolis, 2018.

DUARTE, Newton. Vigotski e o “aprender a aprender": crítica às apropriações neoliberais e pós-modernas da teoria vigotskiana. Campinas, SP: Editores Associados, 2004.

. Sociedade do conhecimento ou sociedade das ilusões? Quatro ensaios crítico-dialéticos em

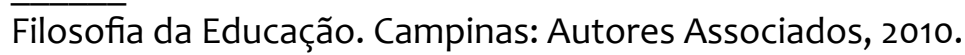

EVANGELISTA, Olinda. (Org.) O que revelam os slogans na política educacional. v. 1. Araraquara, SP: Junqueira e Marin, 2014.

FABRIS, Annateresa. Percorrendo veredas: hipóteses sobre a arte brasileira atual. Revista USP, São Paulo, n. 40, p. 68-77, dez./fev. 1998-99.

FONSECA DA SILVA, Maria Cristina da Rosa; ALVARENGA, Valéria. Metroski . Formação Docente em Arte: percurso e expectativas a partir da lei 13.278/16. Educação e Realidade Edição eletrônica, v. 43, p. 1009-1030, 2018.

FONSECA DA SILVA, Maria Cristina da Rosa, AGOSTINHO, Jéssica Natana e ZANONI, Carolina Pinheiro. As disciplinas pedagógicas no processo formativo do licenciando em artes visuais: sobre a perspectiva do aluno em formação. In: ENCONTRO REGIONAL DA FAEB - SUL, IV.,. Anais... Criciúma: AAESC, 2019. 
SILVA, M. C. R. F.

FONSECA DA SILVA, Maria Cristina R. Panorama brasileiro das licenciaturas em Artes Visuais: dados a partir do Observatório da formação de professores de Artes. In: CONGRESSO NACIONAL DA FEDERAÇÃO DE ARTE/EDUCADORES DO BRASIL, 27.; CONGRESSO INTERNACIONAL DOS ARTE/EDUCADORES, 5.; SEMINÁRIO DE CULTURA E EDUCAÇÃO DE MATO GROSSO DO SUL, 2.. Anais...,Campo Grande, 2017.

FONSECA DA SILVA, Maria Cristina; PERA Luana Pavesi. Formação docente em artes visuais: análises sobre os cursos de Santa Catarina. In: ENCONTRO NACIONAL DA ASSOCIAÇÃO NACIONAL DE PESQUISADORES EM ARTES PLÁSTICAS - ENANPAP, 23., 2014, Belo Horizonte, MG. Anais... [recurso eletrônico]: ecossistemas artísticos / Afonso Medeiros, Lucia Gouvêa Pimentel, Idanise Hamoy, Yacy-Ara Froner (Orgs.). Belo Horizonte: ANPAP; Programa de Pós-graduação em Arte. Belo Horizonte - MG: Editora da UFMG, 2014. p. 3772-3787.

FONSECA DA SILVA, Maria Cristina; HILLESHEIM, Giovana Bianca Darolt; RUSCHEL, Ana Luiza In: ENCONTRO REGIONAL DA FAEB - Sul, IV., Anais... Criciúma; AAESC, 2019.

FONSECA DA SILVA, M. C. R.; SCHILICHITA, Consuelo Alcioni Borba Duarte; HILLSHEIM, Giovana Bianca. A formação do artista-professor-pesquisador: as condições de ensinar, fazer e pesquisar arte. In: ENCONTRO NACIONAL DOS PESQUISADORES EM ARTES PLÁSTICAS, 25., 2016, Porto Alegre - POA. Anais do XXV Encontro da Associação Nacional de Pesquisadores em Artes Plásticas [recurso eletrônico]; Compartilhamentos na arte: redes e conexões / Nara Cristina Santos; Ana Maria Albani de Carvalho; Paula Ramos; Andréia Machado Oliveira (Orgs.). Porto A. São Paulo: ANPAP, 2016. p. 241-255.

GONÇALVES, Monica Hoff. A virada educacional nas práticas artísticas e curatoriais contemporâneas e o contexto de arte brasileiro. 2014. 272 f. Dissertação (Mestrado em Artes Visuais - Programa de Pós-Graduação em Artes Visuais, Universidade Federal do Rio Grande do Sul, Porto Alegre, 2014.

HILLESHEIM, Giovana Bianca Darolt. Um olhar para as pesquisas que abordam a formação de professores de artes visuais: caminhos percorridos e a percorrer. 2014. Dissertação (Mestrado em Artes Visuais) Centro de Artes, Universidade do Estado de Santa Catarina, Florianópolis, 2014.

. Mercado de arte e sua interface com o trabalho docente: estratégias do capitalismo cultural. 2018. Tese (Doutorado em Artes Visuais) - Centro de Artes, Universidade do Estado de Santa Catarina, Florianópolis, 2018.

HUSSAK, Pedro e VIEIRA, Vladimir. Educação estética: de Schiller a Marcuse. (Orgs.). Rio de Janeiro, NAU: EDUR, 2011.

IASI, Mauro Luis. A crise do capital: a era da hipocrisia deliberada. Revista Praiavermelha, Rio de Janeiro, v. 19 n. 1, p. 25-40, jan./jun. 2009.

JAMESON, Fredric. Pós-modernismo: a lógica cultural do capitalismo tardio. São Paulo: Editora Ática, 1997.

MARSIGLIA, A. C. G.; MARTINS, L. M.; LAVOURA, T. N. Rumo à outra didática histórico-crítica: superando imediatismos, logicismos formais e outros reducionismos do método dialético. Revista HISTEDBR On-line, v. 19, p. e019003, 19 mar. 2019.

MAZZEU, Lidiane Teixeira Brasil. A política educacional e a formação de professores. In: MARSIGLIA, Ana Carolina Galvão (Org.). Pedagogia histórico-crítica: 30 anos. Campinas, SP: Autores Associados, 2011. (Coleção Memórias da Educação).

MINISTÉRIO DA EDUCAÇÃO. Conselho Nacional de Educação Câmara de Educação Superior. Resolução n. 1, de 16 de janeiro de 2009. Aprova as Diretrizes Curriculares Nacionais do Curso de Graduação em 
Artes Visuais e dá outras providências. Disponível em: <http://portal.mec.gov.br/cne/arquivos/pdf/2009/rces001_09.pdf>. Acesso em: 27 maio 2019.

MÜLLER, Maristela. A pesquisa na formação de professores: uma análise curricular das licenciaturas em Artes Visuais no Rio Grande do Sul. 2017. Dissertação (Mestrado em Artes Visuais) - Programa de Pós-Graduação em Artes Visuais, Universidade do Estado de Santa Catarina, Florianópolis, 2017.

PERINI, Janine Alessandra. A formação do professor de artes visuais na sociedade capitalista. In: JORNADA DO HISTEDBR - Pedagogia Histórico-Crítica, Educação e Revolução: 100 anos da Revolução Russa, XIV., 2017, Foz do Iguaçu. Foz do Iguaçu. Anais.... Foz do Iguaçu: Programa de Pós-Graduação em Educação. Grupo de Pesquisa em História, Sociedade e Educação no Brasil, 2017. v. 14.

SANTOS SILVA, Clarissa. Arte, tecnologia e formação docente: reverberações nos currículos das licenciaturas em Artes Visuais da Região Nordeste. 2017. 246 f. Dissertação (Mestrado em Artes Visuais) - Programa de Pós-Graduação em Artes Visuais, Universidade do Estado de Santa Catarina, Florianópolis, 2017.

SAVIANI, Dermeval. Educação escolar, currículo e sociedade: o problema da Base Nacional Comum Curricular. Movimento-Revista de Educação, v. 3, p. 54-84, 2016.

. Formação de professores: aspectos históricos e teóricos do problema no contexto brasileiro. Revista Brasileira de Educação, Rio de Janeiro, v. 14, n. 40 jan./abr. 2009. . Escola e democracia. Edição Comemorativa. Campinas: Autores Associados, 2007.

SILVA, Lucas Prestes da. Os métodos educativos para o ensino de artes e suas influências na licenciatura em artes visuais. 2018. 145 f. Dissertação (Mestrado em Artes Visuais) - Programa de Pós-Graduação em Artes Visuais, Universidade do Estado de Santa Catarina, Florianópolis, 2018.

VÁZQUEZ, A. S. As idéias estéticas de Marx. 2. ed. Rio de Janeiro: Paz e Terra, 1978.

VIGOTSKI, Lev. S. Imaginação e criação na infância: ensaio psicológico. Apresentação e comentários de Ana Luiza Smolka. Tradução de Zoia Prestes. São Paulo: Ática, 2009. 
POLÍTICAS E CURRÍCULO NA LICENCIATURA EM ARTES VISUAIS

SILVA, M. C. R. F.

Recebido em: 29/05/2019

Aceito em: 20/08/2019

Publicado em: 03/10/2019 